\title{
Research of ecology-friendly technology for elimination of ammonium from waste water through the use of floating bed
}

\author{
Nikolay Makisha ${ }^{1 \mathrm{a}}$ \\ ${ }^{1}$ Moscow State University of Civil Engineering, 129337, Moscow, Russia
}

\begin{abstract}
The article touches upon integrated treatment of sewage. It reveals description of the research with use of floating feed. Experiment data were the basis to prove effectiveness of floating feed as a way to intensify treatment processes in aeration tanks. The article also includes math treatment of the results to correspond them with laws of enzymatic kinetics.
\end{abstract}

\section{Introduction}

Nitrification/denitrification researches have a long history and strong background in viewpoint of process dependencies and influence of factors of the environment [1]. There are also a large number of technological solutions and constructions towards removal of ammonium compounds out of wastewater by means of aeration tanks as well as biofilters. However there is still a wide scope of work to be done [2].

Among these options treatment quality improvement by means of immobilized biomass seems to be one of the most prospective. Researchers worldwide have already invented various types of materials as well as the technologies to implement them. Polymer materials have certain advantages to be applied for these needs [3, 4].

Researchers of Moscow state university of civil engineering also have a solid base of knowledge in the field of waste water treatment in general and ways how to force it in particular. One of the recent researches was a complicated study aimed at deep ammonium removal by means of floating bed. There are several aims to be pursued: to estimate how a floating bed influences the treatment process, amount of floating bed to be involved, what the treatment duration is etc. [5-8].

\section{Research description}

The research was divided into several stages to set and solve abovementioned tasks consequently [9]. Stage 1 had two subtasks. The first one was to define if a use of floating bed gives any advantage in viewpoint of deep biological treatment. The second subtask was to estimate the concentration of floating bed in the tank that allows to obtain the most efficient results. There were three samples of polymer bed taken for the research. Each of

${ }^{a}$ Corresponding author: nmakisha@gmail.com 
them had a different shape: parallelepiped - type 1 (Figure 1), cube - type 2 (Figure 2) and sphere type 3 (Figure 3); different properties such as volume weight and specific surface (see table 1); and different material of production: polystyrene and polyethylene [10-12].

Table 1. Properties of researched bed

\begin{tabular}{|c|c|c|}
\hline Type of bed & Volume weight, $\mathbf{~ k g} / \mathbf{m}^{\mathbf{3}}$ & Specific surface, $\mathbf{~ m}^{\mathbf{2}} / \mathbf{m}^{\mathbf{3}}$ \\
\hline Type 1 & 22 & 420 \\
\hline Type 2 & 25 & 600 \\
\hline Type 3 & 50 & 620 \\
\hline
\end{tabular}

Samples of floating bed were investigated in the laboratory model in which a traditional technological scheme of biological treatment by means of aeration tank was implemented (Figure 4). Each type of bed was investigated with 10\%, 20\% and 30\% ratio of bed volume to tank volume. Each type of bed has been simultaneously investigated for each three ratios above. A control tank (without bed) has also been installed to verify the results obtained. Treatment duration was 8 hours.

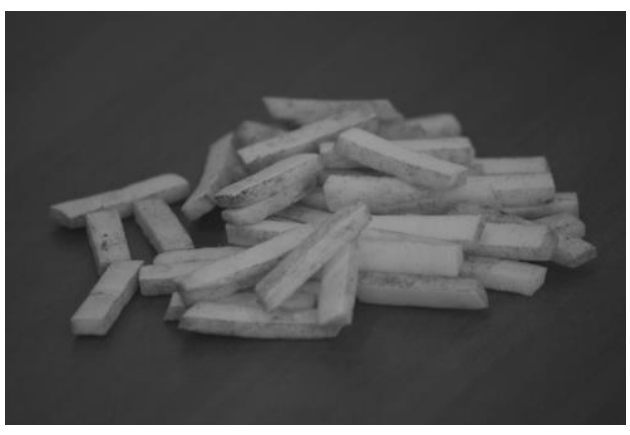

Fig. 1. Floating bed, type 1 .

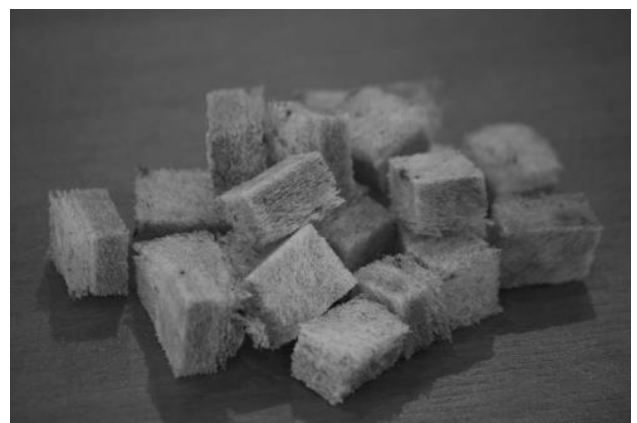

Fig. 2. Floating bed, type 2.

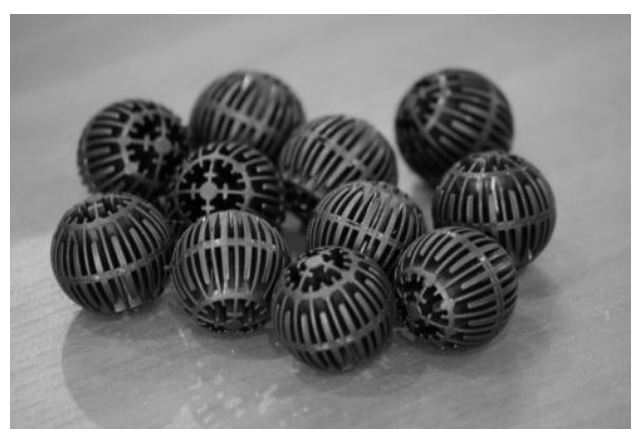

Fig. 3. Floating bed, type 3 .

Research at each stage has been carried out by means of artificial waste water that was by made on peptone basis. Concentration of pollutants for such waste water fully corresponded to common domestic waste water. Sanitary analyses were performed according to acknowledged methods [13-15].

Efficiency of ammonium removal in the tanks with floating bed was constantly higher than in control tank through the whole stage 1. That fact speaks in favour of positive influence of floating bed on processes of biological treatment of waste water. The optimum ratio between bed and tank volumes was determined on the basis of laboratory experiments for each type of bed and further mathematical processing of practical data. Load on sludge 
and velocity of oxidation for both BOD and NH4 were calculated. The math description of the dependence between activity of enzyme reaction and substrate concentration was given according to the Michaelis - Menten equation and graphical representation of Lineweaver Burk $[9,11]$.

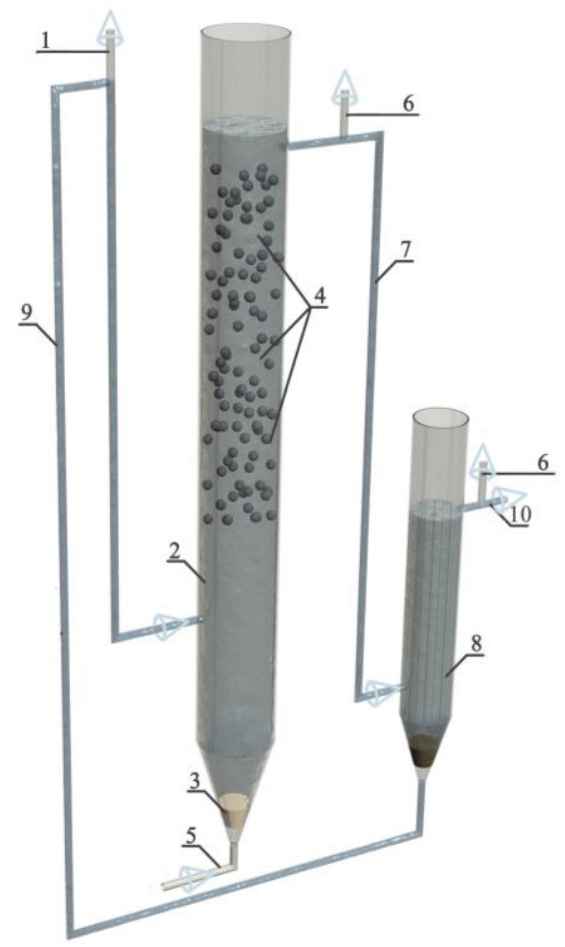

Fig. 4. Laboratory model, stage 1: 1 - inlet; 2 - aeration tank; 3 - aerator; 4 - floating bed; 5 - air inlet; 6 - compressor; 7 - inlet of sludge mixture to secondary clarifier; 8 - secondary clarifier; 9 recirculation of active sludge; 10 - discharge of treated water.

Floating bed of type 1 showed its best results for research aims with a ratio of $10 \%$, meanwhile for the floating beds of type 2 and 3 the optimum was $20 \%$ of tank volume. Table 2 shows average values of inlet and outlet pollutants' concentrations (BOD and $\mathrm{NH}_{4}$ ) for models with optimum values of ratio above.

Table 2. Average results for stage 1

\begin{tabular}{|l|c|c|c|c|c|c|}
\hline \multirow{2}{*}{ Type of bed } & \multicolumn{7}{|c|}{ Average values, mg/l } \\
\cline { 2 - 7 } & \multicolumn{3}{|c|}{ BOD5 } & \multicolumn{3}{c|}{$\mathrm{NH}_{4}$} \\
\cline { 2 - 7 } & In & Out & E, \% & In & Out & E, \% \\
\hline Type 1 & 155 & 8 & 95 & 22,1 & 3,1 & 86 \\
\hline Type 2 & 161 & 6,7 & 96 & 26,6 & 4,9 & 82 \\
\hline Type 3 & 144 & 6,4 & 96 & 22,7 & 4,3 & 81 \\
\hline Control & 150 & 12,6 & 92 & 23,0 & 10,3 & 55 \\
\hline
\end{tabular}

Thus, experiments helped to achieve a proof that treatment (organic and $\mathrm{NH}_{4}$ pollution) processes have been intensified through the use of floating beds of various types. Despite of the more or less positive results, discharge concentrations especially for $\mathrm{NH}_{4}$ were still far from regulation requirements, so further investigation had to be carried out. The first alteration happened was a substitution technological scheme. It was enhanced by the 
introduction of biofiltration reactor on the second step of treatment while the same aeration reactor was used at the first step. There were three laboratory models under simultaneous investigation - each with its' own type of floating bed installed. Biofiltration tanks has the same bed for each models - cylindrical polymer bed with fibers of polyethylene on its' surface [12].

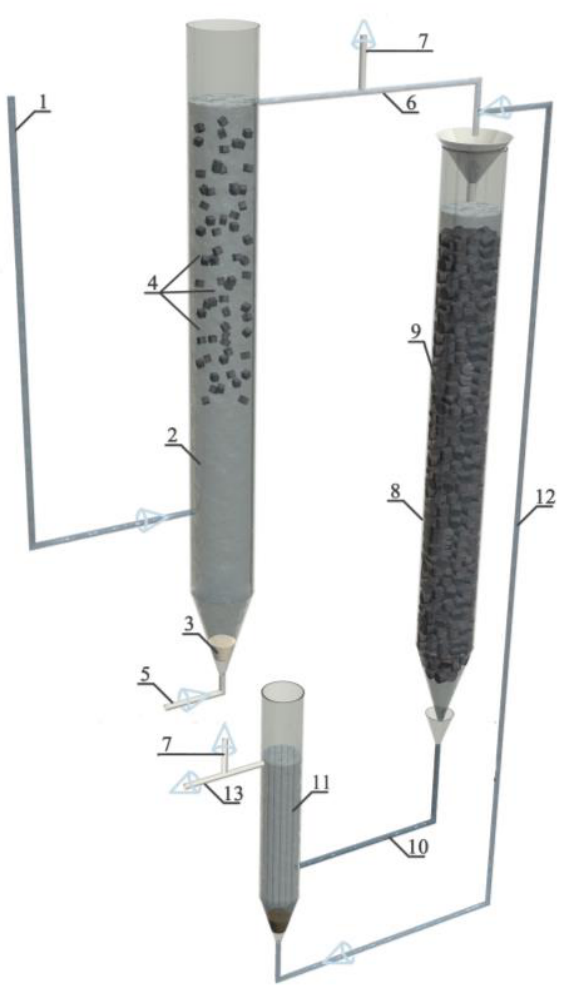

Fig. 5. Laboratory model, stage 2: 1 - inlet; 2 - aeration reactor; 3 - aerator; 4 - floating bed; 5 - air inlet; 6 - compressor; 7 - outlet of treated water to biofiltration reactor; 8 - biofiltration reactor; 9 fixed bed of biofiltration reactor; 10 - discharge of water to secondary clarifier; 11 - secondary clarifier; 12 - recirculation of active sludge; 13 - discharge of treated water.

Once the optimum ratios had been determined on the stage 1 all further researches were made on this basis. Through the whole stage all three types of feed were working simultaneously. Oxygen concentration was at a level of $7 \mathrm{mg} / 1$ during the whole stage 2 . It was marked that aeration reactor works in a more stable way if no recirculation flow I provided. Concentrations of free and immobilized sludge were near $0.2 \mathrm{mg} / \mathrm{l}$ and $0.9 \mathrm{mg} / 1$ correspondingly. After the overview of the analyses results it was defined, that type 2 showed more efficient treatment (see table 3). The entire efficiency of system grew; however, the regulation requirements were not still met for nitrates and nitrites.

Table 3. Average results for stage 2

\begin{tabular}{|l|c|c|c|c|c|c|}
\hline \multirow{2}{*}{ Type of bed } & \multicolumn{7}{|c|}{ Average values, mg/l } \\
\cline { 2 - 7 } & \multicolumn{7}{|c|}{ BOD 5} & \multicolumn{3}{c|}{$\mathrm{NH}_{4}$} \\
\cline { 2 - 7 } & In & Out & E, \% & In & Out & E, \% \\
\hline Type 1 & 162 & 31 & 81 & 23,5 & 6,7 & 74 \\
\hline Type 2 & 164 & 14,6 & 91 & 21,3 & 2,7 & 89 \\
\hline Type 3 & 171 & 21,1 & 88 & 25 & 14 & 40 \\
\hline
\end{tabular}


Math processing of the results allowed obtaining the values of velocity of oxidation and denitrification. The Michaelis - Menten equation can be written as follows:

$$
\begin{aligned}
& V=\frac{V_{\max } \cdot S}{k_{m}+S}=\frac{47.6 \cdot L_{e x}}{3.3+L_{e x}} \\
& V=\frac{V_{\max } \cdot S}{k_{m}+S}=\frac{14.3 \cdot N H_{4 e x}}{4+N H_{4 e x}}
\end{aligned}
$$

The investigation towards enhacement of removal of organic pollution and nitrogen compounds were continued at the stage 3. The two-step scheme of treatment was still in use, however two steps changed their places - biofiltration reactor was on the first step, aeration reactor - on the second (Figure 6). There was also intermediate clarifier installed after the biofiltration reactor to hold the excessive biofilm inside. That measure helped to keep relatively low sludge concentration inside aeration reactor that was quite efficient on the previous stage.

\begin{tabular}{|c|c|c|c|c|c|c|}
\hline \multirow[t]{3}{*}{ Type of bed } & \multicolumn{6}{|c|}{ Average values, mg/l } \\
\hline & \multicolumn{3}{|c|}{$\mathrm{BOD}_{5}$} & \multicolumn{3}{|c|}{$\mathrm{NH}_{4}$} \\
\hline & In & Out & $\mathrm{E}, \%$ & In & Out & $\mathrm{E}, \%$ \\
\hline Type 1 & 49,3 & 15,7 & 68 & 14,1 & 2,3 & 83 \\
\hline Type 2 & 39,4 & 9,5 & 76 & 27 & 17 & 37 \\
\hline Type 3 & 49,6 & 3.0 & 92 & 11.3 & 0,4 & 97 \\
\hline
\end{tabular}

Table 4. Average results for stage 3

The highest treatment efficiency about $99 \%$ on the stage 3 was obtained by the floating bed type 3 that made concentrations of $\mathrm{BOD}, \mathrm{NH}_{4}, \mathrm{NO}_{2}$ and $\mathrm{NO}_{3}$ meeting the regulation requirements (see table 4). Oxygen concentrations remained at the same level $-6-7 \mathrm{mg} / \mathrm{l}$, sludge concentrations for free floating and fix phase were $0.8 \mathrm{mg} / \mathrm{l}$ and $0.3 \mathrm{mg} / \mathrm{l}$ correspondingly.

Math processing of the results allowed obtaining the values of velocity of oxidation and denitrification. The Michaelis - Menten equation can be written as follows:

$$
\begin{aligned}
& V=\frac{V_{\max } \cdot S}{k_{m}+S}=\frac{18.9 \cdot L_{e x}}{4.17+L_{e x}} \\
& V=\frac{V_{\max } \cdot S}{k_{m}+S}=\frac{5.56 \cdot N H_{4 e x}}{0.67+N H_{4 e x}}
\end{aligned}
$$




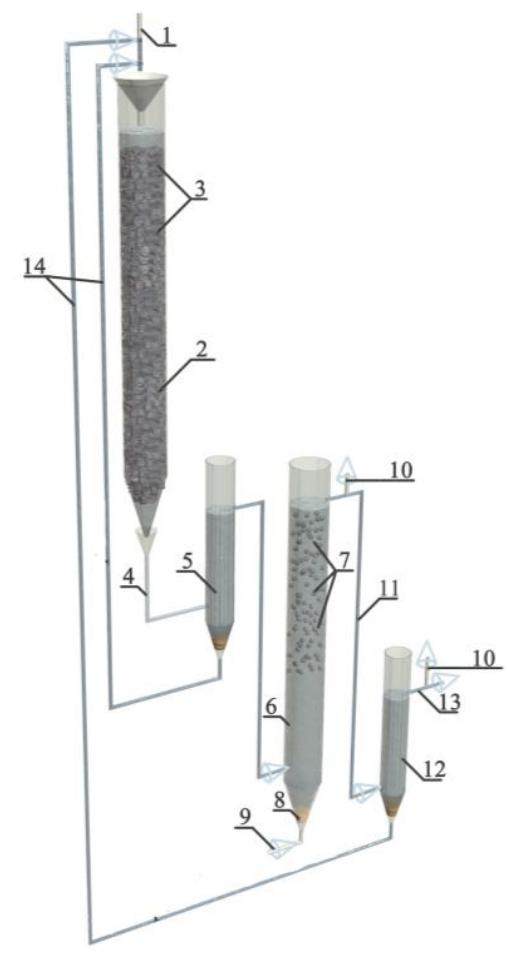

Fig. 6. Laboratory model, stage 3: 1 - inlet; 2 - biofiltration reactor; 3 - fixed bed of biofiltration reactor; 4 - discharge of water to intermediate clarifier; 5 - intermediate clarifier; 6 - compressor; 7 floating bed; 8 - aerator; 9 - air inlet; 10 - air discharge: 11 - discharge of water to secondary clarifier; 12 - secondary clarifier; 13 - discharge of treated water; 14 - recirculation of active sludge.

\section{Conclusion}

Experiments proved confirmed that use of floating bed with ratio of $20 \%$ of bed volume to aeration tank volume enhances the efficiency of biological treatment of waste water and removal of organic pollution and nitrogen compounds

The research validated the stability of biological system with the use of immobilized sludge and under the concentration of free floatinf sludge below $0.8 \mathrm{mg} / 1$.

Low sludge concentration in the aeration tank results in low excessive sludge production that reduces the cost of sludge treatment to make the whole treatment process more energy efficient.

\section{References}

1. V.A. Vavilin, Duration of biomass exchange and destruction of organic compound in systems of biological treatment (1986)

2. N.A. Zaletova, Urban wastewater treatment from biogenic substances: nitrogen and phosphorus: the dissertation ... of doctor of technical sciences (1999)

3. N. Makisha, V. Scherbakov, A. Smirnov, E. Scherbina, IJAER, 10, 24, 44347-44349 (2015) 
4. V. Scherbakov, E. Gogina, T. Schukina, N. Kuznetsova, N. Makisha, E. Poupyrev, IJAER. 10, 21, 44353-44356 (2015)

5. E. Gogina, I. Gulshin, Pr. Eng., 117, 107-113 (2015)

6. I. Gulshin, A. Kuzina, IJAER, 10, 21, 42618-42623 (2015)

7. E.S. Gogina, O.V. Yantsen, O.A. Ruzhitskaya, AMM,580-583, 2354-2357 (2014)

8. O.A. Ruzhitskaya, E.S. Gogina, AMR, 919-921, 2141-2144 (2014)

9. N. Makisha, E. Gogina, AMM, 361-363, 632-635 (2013)

10. O.A. Ruzhitskaya, E.S. Gogina, AMR, 919-921, 2153-2156 (2014)

11. Elena Gogina, Nikolay Makisha, AMM, 587-589, 636-639 (2014)

12. N. Makisha, O. Yantsen, AMM, 587-589, 640-643 (2014)

13. N. Makisha, E. Gogina, AMM, 587-589, 644-647 (2014)

14. N. Makisha, Y. Voronov, E. Poupyrev, V. Volshanik, IJAER, 10, 21, 41919-41922 (2015)

15. N. Zaletova, Y. Voronov, N. Makisha, IJAER, 10, 21, 42454-42455 (2015) 